\title{
Erratum
}

\section{Die paramagnetische Suszeptibilität eines nicht kugelsymmetrischen Systems}

Hermann Hartmann, Regina Schuck and Jürgen Radtke

Theoret. Chim. Acta (Berl.) 42, 1 (1976)

Wir möchten folgende in der obigen Publikation enthaltene Irrtiimer korrigieren:

Zeile 2: Feldstärke $\mathfrak{( 5}$ sollte heißen: Feldstärke $\mathfrak{H}$.

Zeile 4: mit einem Brennpunkt sollte heißen: mit einem Massenpunkt.

Zeile 10: Magnetfeld ((5) sollte heißen: Magnetfeld $\mathfrak{S}$.

Eingegangen am 3. Dezember 1976 